\title{
Effect of Rare Earth Y on Properties of Nanosized 90W-7Ni-3Fe Composite Powder Fabricated by Spray Drying-Hydrogen Reduction
}

\author{
Y.-Z. Ma, Liu Wensheng, Huang Baiyun, and Fan Jinglian \\ State Key Laboratory of Powder Metallurgy, Central South University, Changsha 410083, China \\ Correspondence should be addressed to Y.-Z.Ma, yunzhum@163.com
}

Received 6 July 2007; Accepted 11 January 2008

Recommended by Jun Lou

(W,Ni,Fe) composite oxide powder synthesized by spray drying was reduced at $700^{\circ} \mathrm{C}$ for 90 minutes in $\mathrm{H}_{2}$ atmosphere. The effect of rare earth $\mathrm{Y}$ on $\mathrm{H}_{2}$ reduction of $(\mathrm{W}, \mathrm{Ni}, \mathrm{Fe}$ ) composite oxide powder was studied. Phase composition, crystalline size, and particle morphology of the reduced powder have been measured by X-ray diffraction and scanning electron microscope (SEM). Fsss particle size and special surface area of the reduced powder were also measured and analyzed. The result showed that new phase $\mathrm{Y}\left(\mathrm{Ni}_{0.75} \mathrm{~W}_{0.25}\right) \mathrm{O}_{3}$ appeared in the reduced powder and particle morphology was nearly spherical or polyhedron by $\mathrm{Y}$ additions. The higher the rare earth element content was, the bigger the influencing on particle morphology was. When the rare earth Y content was under $0.8 \%$, with the increase of the rare earth element content, $d_{\mathrm{BET}}$, Fsss, and crystal sizes of the reduced powder decreased greatly.

Copyright (C) 2008 Y.-Z. Ma et al. This is an open access article distributed under the Creative Commons Attribution License, which permits unrestricted use, distribution, and reproduction in any medium, provided the original work is properly cited.

\section{INTRODUCTION}

Tungsten-based heavy alloys, which are used as kinetic energy penetrators, counter weights, radiation shields, and electrical contacts due to their high density, strength, and ductility, are two-phase composites produced by liquid phase sintering mixed elemental tungsten, nickel, and iron powders. Typical compositions have $90 \mathrm{wt} \%$ tungsten with the balance nickel and iron, usually in the ratio of $7: 3$ [1].

Nanostructured tungsten-based alloys possess very high properties, which put high demands on the manufacture process for both powders and bulk alloys. High-energy ball milling, which is a well-known process for preparing amorphous alloyed powders, has been considered as a powderful technique due to relative inexpensive equipment [2]. However, it takes tens of hours to fabricate nanosized W-Ni-Fe composite powder for high-energy milling technique [3], so the milling efficiency is very low. Meanwhile, high-energy milling could bring inclusions. Spray drying process is a useful technique for synthesizing numerous nanostructured materials due to its simplicity and various elements homogeneous dispersibility $[4,5]$. Previous studies have discussed preparation and reduction mechanisms of
(W,Ni,Fe) composite oxide powder by spray drying [6-8]. In this paper, effects on the reduced powder properties with $\mathrm{Y}$ additions were studied by previous reduced conditions optimized at $700^{\circ} \mathrm{C}$ for 90 minutes.

\section{EXPERIMENTAL}

The raw materials in this experiment included the $\left(\mathrm{NH}_{4}\right)_{6} \mathrm{H}_{2} \mathrm{~W}_{12} \mathrm{O}_{40} \cdot x \mathrm{H}_{2} \mathrm{O}, \mathrm{Ni}\left(\mathrm{NO}_{3}\right)_{2} \cdot 6 \mathrm{H}_{2} \mathrm{O}, \mathrm{Fe}\left(\mathrm{NO}_{3}\right)_{3} \cdot$ $9 \mathrm{H}_{2} \mathrm{O}, \mathrm{Y}\left(\mathrm{NO}_{3}\right)_{2} \cdot 6 \mathrm{H}_{2} \mathrm{O}$, and surfactant PEG-1000. First, the $\left(\mathrm{NH}_{4}\right)_{6} \mathrm{H}_{2} \mathrm{~W}_{12} \mathrm{O}_{40} \cdot x \mathrm{H}_{2} \mathrm{O}, \mathrm{Ni}\left(\mathrm{NO}_{3}\right)_{2} \cdot 6 \mathrm{H}_{2} \mathrm{O}$, and $\mathrm{Fe}\left(\mathrm{NO}_{3}\right)_{3} \cdot 9 \mathrm{H}_{2} \mathrm{O}$ were added in distilled water by a composition ratio of $90 \mathrm{wt} \% \mathrm{~W}-7 \mathrm{wt} \% \mathrm{Ni}-3 \mathrm{wt} \% \mathrm{Fe}$ and produced solution with $0.2,0.4,0.6,0.8 \mathrm{wt} \% \mathrm{Y}$ additions by $\mathrm{Y}\left(\mathrm{NO}_{3}\right)_{2} \cdot 6 \mathrm{H}_{2} \mathrm{O}$ (theoretical content calculation), respectively. Secondly, the solution was changed into solution colloid by adjusting $\mathrm{pH}$ value, and $0.5 \mathrm{~g} \cdot \mathrm{L}^{-1}$ PEG-1000 was added. Finally, the (W,Ni,Fe) precursor oxide powder was fabricated by drying spraying of solution colloid, then the nanosized $90 \mathrm{~W}-7 \mathrm{Ni}-3 \mathrm{Fe}$ composite powder including different $\mathrm{Y}$ additions was fabricated by reduction of the $(\mathrm{W}, \mathrm{Ni}, \mathrm{Fe})$ precursor oxide powder in the hydrogen-atmosphere at $700^{\circ} \mathrm{C}$ for 90 minutes. 
Special surface areas of the reduced powder were measured by the nitrogen adsorption method. The Fsss sizes of the reduced powder were measured by the Fisher testing method. The phase compositions and crystal sizes of the reduced powder were tested and analyzed with Rigaku $\mathrm{D} / \mathrm{max} 2550 \mathrm{VB}^{+} 18 \mathrm{Kw} \mathrm{X}$-ray diffraction made in Japan. The reduced powders were dispersed by ultrasonic wave for 30 minutes, whose morphology images were observed with the JSM-5600LV type scanning electron microscope (SEM) made by JEOL cop.

\section{RESULTS AND DISCUSSION}

\subsection{Effect of rare earth $Y$ on phase composition of 90W-7Ni-3Fe composite powder}

Figure 1 showed curves between the $\mathrm{Y}$ additions and phase compositions of the reduced composite powder at $700^{\circ} \mathrm{C}$ for 90 minutes. It was seen from Figure 1 that the phase compositions of the reduced powder were $\mathrm{W}$ and $\gamma$ - $(\mathrm{Ni}, \mathrm{Fe})$ without the rare earth $\mathrm{Y}$ addition, new phase $\mathrm{Y}\left(\mathrm{Ni}_{0.75} \mathrm{~W}_{0.25}\right) \mathrm{O}_{3}$ was appeared when adding $0.4 \mathrm{wt} \% \mathrm{Y}$. With the increase of $\mathrm{Y}$ additions from $0.4 \mathrm{wt} \%$ to $0.8 \mathrm{wt} \%$, intensity of new phase $\mathrm{Y}\left(\mathrm{Ni}_{0.75} \mathrm{~W}_{0.25}\right) \mathrm{O}_{3}$ raised in X-ray diffraction graph.

\subsection{Effect of rare earth $Y$ on properties of $90 \mathrm{~W}-7 \mathrm{Ni}$ - $3 \mathrm{Fe}$ composite powder}

Figure 2 showed curves between the $d_{\mathrm{BET}}$ particle sizes, Fsss particle sizes, and crystal sizes of the reduced powder and the $\mathrm{Y}$ additions. The crystal sizes of the reduced powder were decreased with increase of the $\mathrm{Y}$ additions from Figure 2(a). High $\mathrm{Y}$ addition has better effect on inhibition for crystal size than low $\mathrm{Y}$ addition. The $d_{\mathrm{BET}}$ and Fsss particle sizes of the reduced powder with some $\mathrm{Y}$ additions were much smaller than those of the reduced powder without $\mathrm{Y}$ addition from Figures 2(b) and 2(c). Even if $0.2 \mathrm{wt} \% \mathrm{Y}$ was added, the $d_{\mathrm{BET}}$ and Fsss particle sizes of the reduced powder declined obviously. With the increase of water vapor produced during reduction process, tungsten oxide and water vapor synthesized volatiling $\mathrm{WO}_{x} \cdot \mathrm{H}_{2} \mathrm{O}$, that is $\mathrm{WO}_{2}(\mathrm{OH})_{2}$, which deposited on the surface of metal tungsten powder by vapor transference, and led to growth of particles [9]. The process sequenced as

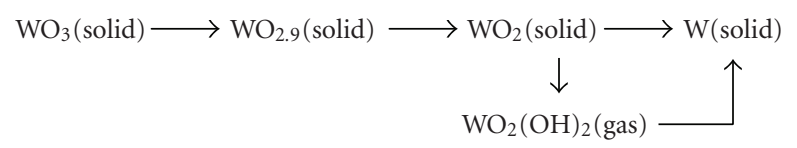

When rare earth $\mathrm{Y}$ was added, new phase $\mathrm{Y}\left(\mathrm{Ni}_{0.75} \mathrm{~W}_{0.25}\right) \mathrm{O}_{3}$ formed and adsorbed on the surface of tungsten particles. Meanwhile, new phase $\mathrm{Y}\left(\mathrm{Ni}_{0.75} \mathrm{~W}_{0.25}\right) \mathrm{O}_{3}$ can effectively prevent $\mathrm{WO}_{2}(\mathrm{OH})_{2}$ from producing and decreasing vapor transference, which inhibited effectively $\mathrm{W}$ particles from growing up.

\subsection{Effect of rare earth $Y$ on morphology images of 90W-7Ni-3Fe composite powder}

SEM morphology images of the reduced composite powder were listed in Figure 3. From Figure 3, the reduced W-Ni-Fe

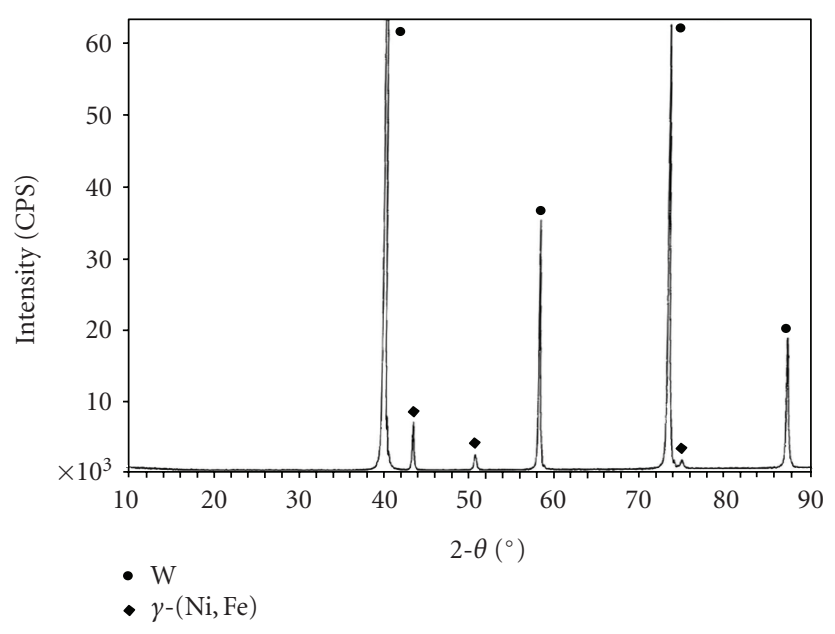

(a)

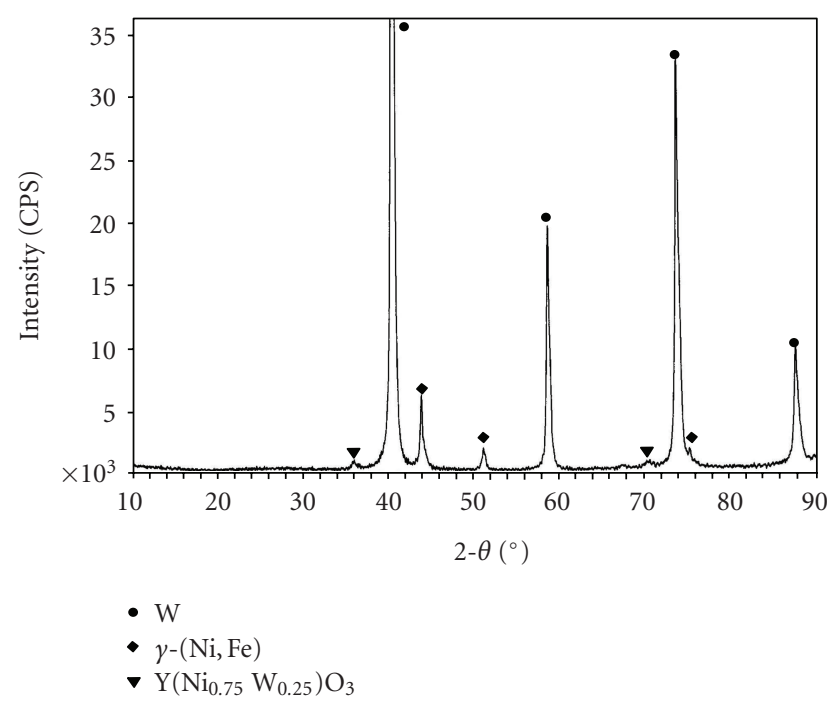

(b)

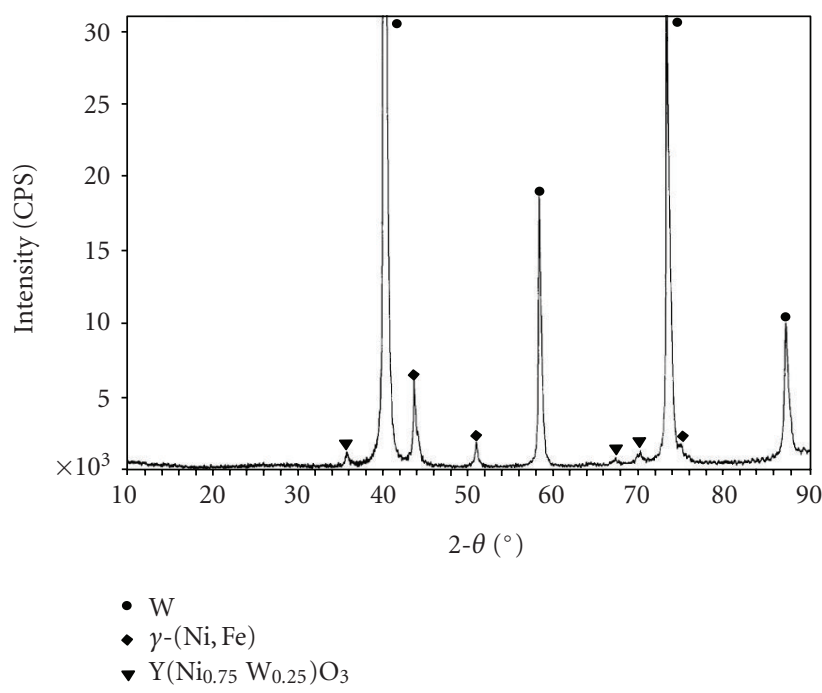

(c)

FIGURE 1: X-ray diffraction images of W-Ni-Fe composite powder reduced: (a) no Y addition; (b) $0.4 \mathrm{wt} \% \mathrm{Y}$; (c) $0.8 \mathrm{wt} \% \mathrm{Y}$. 


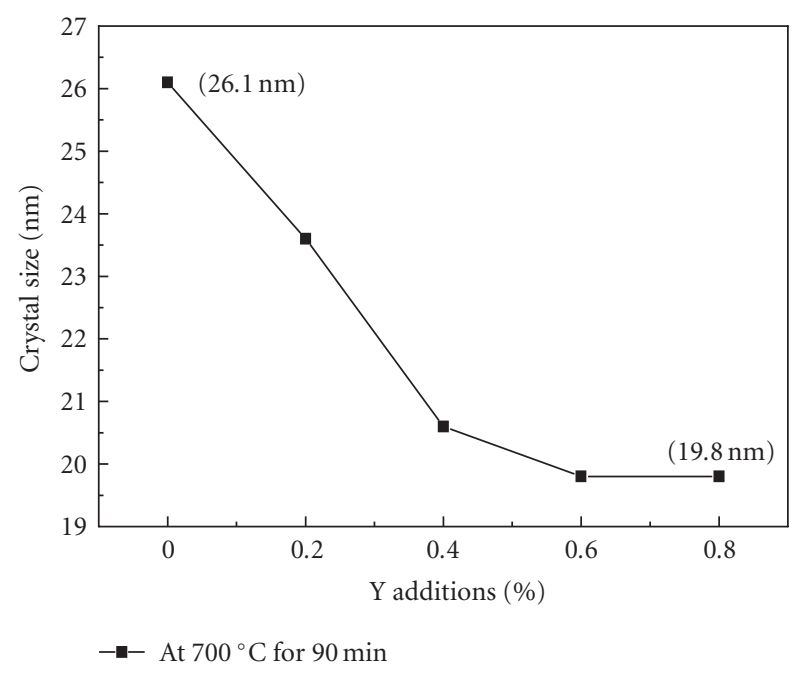

(a)

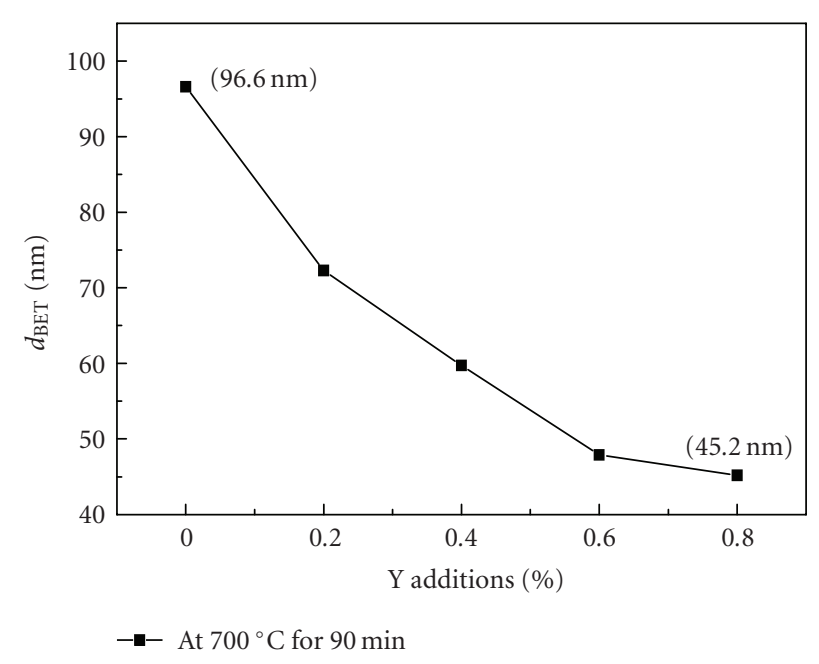

(b)

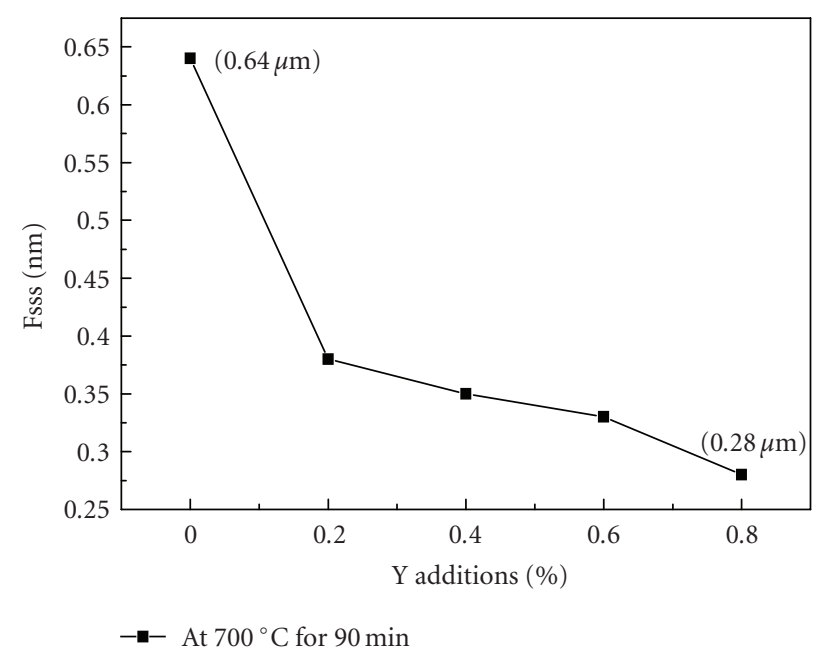

(c)

Figure 2: Properties curves of the reduced powder for different $Y$ additions: (a) crystal sizes; (b) $d_{\mathrm{BET}}$; (c) Fsss.

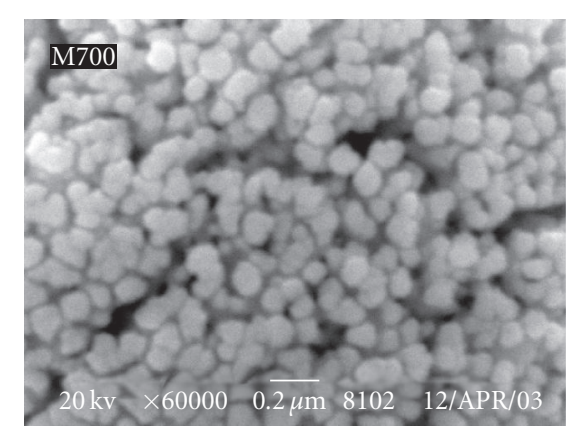

(a)

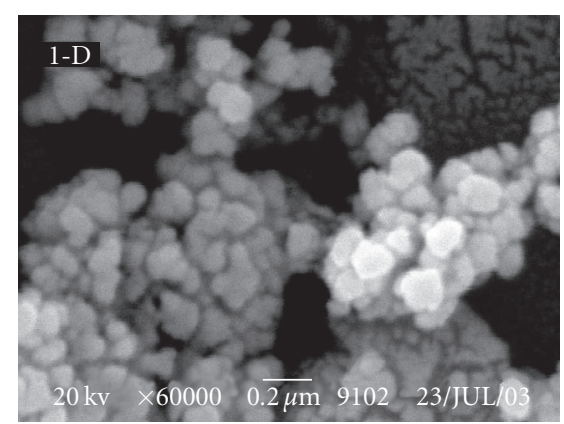

(b)

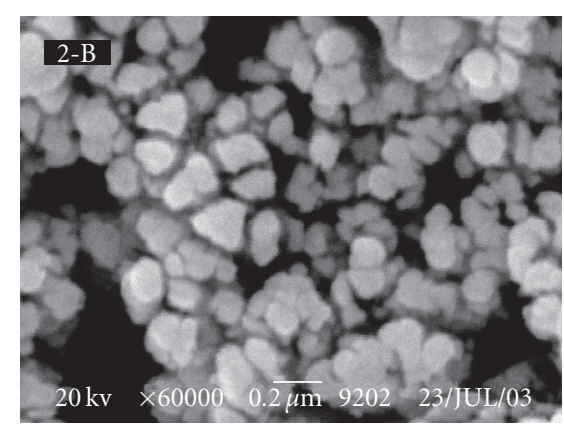

(c)

FIGURE 3: Morphology images of the reduced powder for different Y additions (SEM): (a) no Y addition; (b) 0.4 wt\% Y; (c) 0.8 wt.\% Y.

composite powder by rare earth $\mathrm{Y}$ additions was more homogeneous dispersibility than that of no $\mathrm{Y}$ addition. Meanwhile, with the increase of $\mathrm{Y}$ addition, effect of rare earth on dispersibility of the reduced powder enlarged obviously. It was also seen clearly from Figure 3 that, powder particle morphology with rare earth $\mathrm{Y}$ addition has changed, the particle morphology was spherical without rare earth Y, but the powder particle morphology was nearly spherical with $0.4 \mathrm{wt} \% \mathrm{Y}$ and polyhedral with $0.8 \mathrm{wt} \% \mathrm{Y}$. The higher the $\mathrm{Y}$ additions were, the greater the effect on powder particle morphology was. Because energy state of some crystal interface has changed when some rare earth $\mathrm{Y}$ were added, which forced crystal quickly growth up at some directions and inhibited other directions from growthing up. With the increase of rare earth Y, tendency of preferential orientation growthing was more obvious $[10,11]$. 


\section{CONCLUSION}

(1) The phase compositions of the reduced powder were $\mathrm{W}$ and $\gamma-(\mathrm{Ni}, \mathrm{Fe})$ without the rare earth $\mathrm{Y}$ addition, but new phase $\mathrm{Y}\left(\mathrm{Ni}_{0.75} \mathrm{~W}_{0.25}\right) \mathrm{O}_{3}$ was appeared by adding $0.4 \mathrm{wt} \% \mathrm{Y}$. With the increase of $\mathrm{Y}$ additions from $0.4 \mathrm{wt} \%$ to $0.8 \mathrm{wt} \%$,

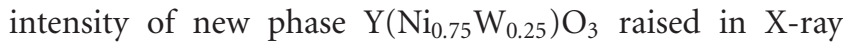
diffraction graph.

(2) With increase of $Y$ additions in the range of $0.8 \mathrm{wt} \%$, the crystal, $d_{\mathrm{BET}}$, and Fsss sizes of the reduced $\mathrm{W}-\mathrm{Ni}-\mathrm{Fe}$ composite powder were decreased from $26.1 \mathrm{~nm}, 96.6 \mathrm{~nm}$, $0.64 \mu \mathrm{m}$ to $19.8 \mathrm{~nm}, 45.2 \mathrm{~nm}, 0.28 \mu \mathrm{m}$, respectively.

(3) Rare earth Y possessed great influence on powder particle morphology. The particle morphology is spherical without rare earth $\mathrm{Y}$, but the particle morphology is nearly spherical by adding $0.4 \mathrm{wt} \% \mathrm{Y}$ or polyhedron with $0.8 \mathrm{wt} \%$ $\mathrm{Y}$ addition. The higher rare earth content is, the bigger influencing on particle morphology is.

\section{ACKNOWLEDGMENTS}

The authors thank the National Natural Science Foundation of China (Grant no. 50774098) and the Creative research group of National Natural Science Foundation of China (Grant no. 50721003) for the financial support.

\section{REFERENCES}

[1] Y. Weihong, "Processing industry of refractory metals in our country between centuries," Rare Metal Materials and Engineering, vol. 27, supplement 1, pp. 1-8, 1998, (Chinese).

[2] H. J. Ryu, S. H. Hong, and W. H. Baek, "Mechanical alloying process of 93W-5.6Ni-1.4Fe tungsten heavy alloy," Journal of Materials Processing Technology, vol. 63, no. 1-3, pp. 292-297, 1997.

[3] J. Sun, F. Zhang, and J. Shen, "Characterizations of ball-milled nanocrystalline WC-Co composite powders and subsequently rapid hot pressing sintered cermets," Materials Letters, vol. 57, no. 21 , pp. 3140-3148, 2003.

[4] M. H. Manusson and K. Deppert, "Single-crystalline of tungsten nanoparticles produce by thermal decomposition of tungsten exacarbonyl," Journal of Materials Research, vol. 15, no. 7, pp. 1564-1569, 2000.

[5] L. E. McCandlish, B. H. Kear, and S. J. Bhatia, World Patent, WO91/07244, 1991.

[6] M. Yunzhu, H. Baiyun, F. Jinglian, et al., "Reduction procedure study of (W,Ni,Fe) composite oxide powder," Journal of Central South University, vol. 35, no. 1, pp. 16-20, 2004, (Chinese).

[7] W. D. Schubert, "Kinetics of the hydrogen reduction of tungsten oxides," International Journal of Refractory Metals \& Hard Materials, vol. 9, no. 4, pp. 178-191, 1990.

[8] A. Lackner, "Hydrogen reduction of blue tungsten oxide," International Journal of Refractory Metals \& Hard Materials, vol. 14, no. 5-6, pp. 383-391, 1996.

[9] W. Zunan, "Summarizing of modern times reduction theory of tungsten," Cemented Carbide, vol. 8, no. 1, pp. 14-21, 1991, (Chinese).

[10] Y. Yang, Z. Meiling, and L. Hanguang, "Effect of La and Y on hydrogenolysis of blue W oxide," Rare Metal Materials and Engineering, vol. 23, no. 5, pp. 52-55, 1994, (Chinese).
[11] Z. Jiuxing, L. Xinyu, Z. Tieyong, et al., "The effect of rare earth element La on the doped tungsten powder morphology and the properties of the bars," Rare Metal Materials and Engineering, vol. 20, no. 6, pp. 28-32, 1991, (Chinese). 

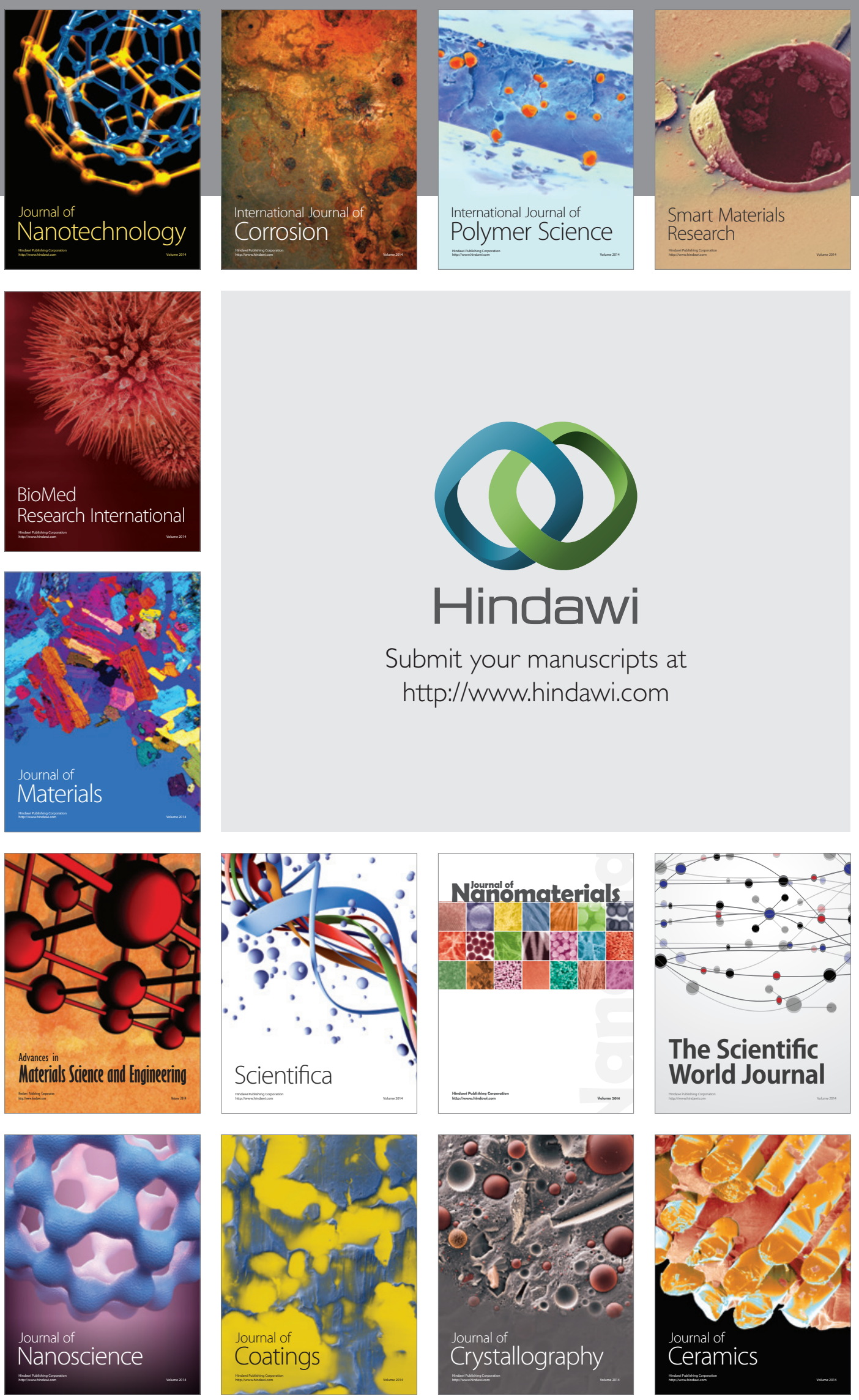

The Scientific World Journal

Submit your manuscripts at

http://www.hindawi.com

\section{World Journal}

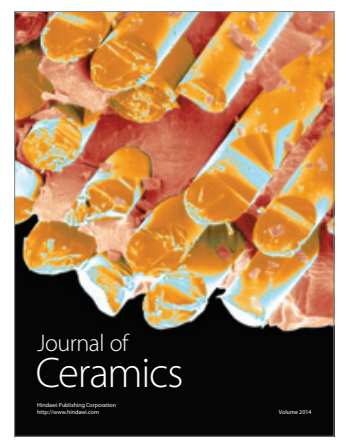

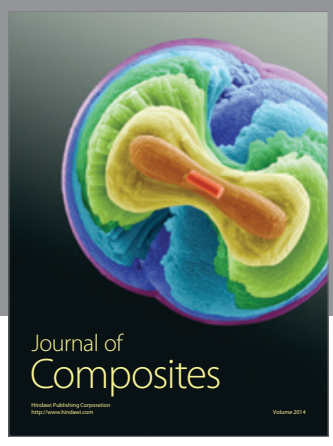
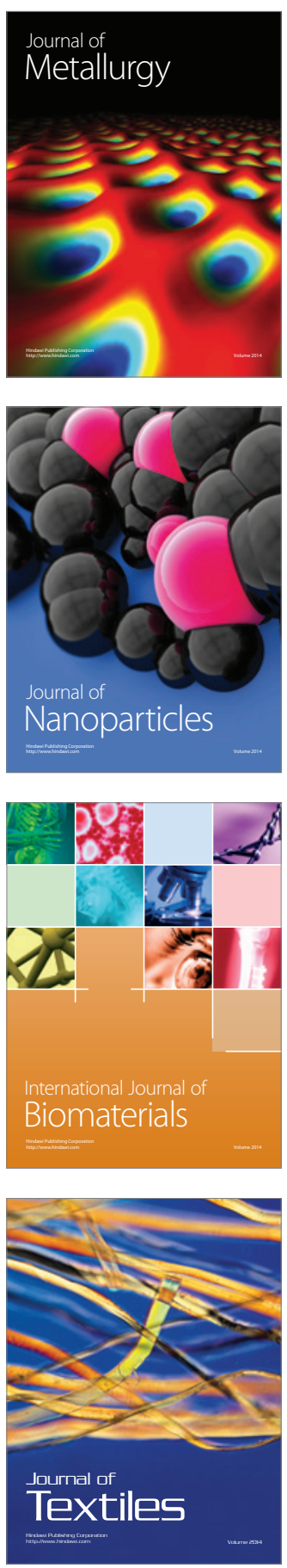